in the form of radiation, their life-period accordingly being much less; (3) different life-periods are coordinated with the 1,2 , etc., state of transversal oscillation $\left(v=673 \mathrm{~cm}^{-1}\right)$.

In this way, without any new assumption, the dependence on temperature of the apparent vibrational specific heat can be calculated as it should result from measuring the velocity of sound at a frequency of $3000 \mathrm{sec}^{-1}$, and a curve (Fig. I) is thus obtained $\left(C^{\prime}{ }_{s}\right)$ conforming quite satisfactorily to the experimental data at high temperatures especially. ${ }^{4}$ In comparison to the normal course $\left(C_{s}\right)$ of the curve, it diverges at high and low temperatures, and approaches it at room temperature. In this way further valuable consequences may be drawn from the work of Dixon, Campbell, and Parker.

In these circumstances, the very different interpretations given by Ibbs and Wakeman ${ }^{5}$ may be dispensed with.

Physical Institute,

University of Marburg, March 29.

I Ann. d. Phys., 11, 761 and $777 ; 1931$

2 Naturw, 20, $85 ; 1932$.

NATURE, 129, 200, Feb. 6, 1932

- Dixon, Campbell, and Parker, Proc. Roy. Soc., 100, 22; 1922; and 105,$212 ; 1924$ : unpublished measurements from this institute.

5 Proc. Roy. Soc., A, 134, 636; 1932.

\section{Types of Iridescent Clouds}

In the winter of $1930-31$, I was measuring the height of the aurora in northern Ontario. On one occasion there had been a well-developed single arc which had remained unusually steady throughout the evening, and I was surprised to see at dawn next morning a light band of cloud stretched in a perfect bow from horizon to horizon, and in what seemed to be the exact position that the aurora had occupied. The cloud was of a yellowish, smoky appearance, and quite unlike the cirrus formation present in other parts of the sky. It faded away about sunrise.

The height of the particular auroral are was not measured, but it cannot have been less than $70 \mathrm{~km}$., and probably was about $100 \mathrm{~km}$. Of course, daylight precluded height measurement of the actual cloud; but if it was connected with the aurora, and therefore likely to have been about the same distance away, the resemblance in apparent curvature would indicate a similar height.

I have seen mention in early writers of similarity between certain cloud-forms and auroræ, but a connexion is hard to explain.

3515 University Street,

$$
\text { H. S. WYNNE-EDWARDS. }
$$

\section{Montreal, Quebee, April 21.}

IN his account of Prof. Størmer's observations on iridescent clouds, Prof. S. Chapman refers to their rapid internal motion. ${ }^{1}$ It is perhaps worth while to put on record that this was also a characteristic of the luminous night clouds of the midsummer of 1885 , two years after the Krakatoa eruption. I was living in London at the time, at a house in the City, and obtained from the roof a clear view of the northern horizon at midnight, doubtless the clearer for the miles of built-up area between. The belt of brilliantly white cloud (not iridescent) lying just above the horizon was in rapid internal movement ; after turning away one's eyes for a few seconds the forms of component wisps were found to be quite changed. Considering the immense distance (probably 400 miles), the movement must have been very rapid indeed. It is obvious that, to be visible from London at midnight, these luminous night clouds were much higher than the iridescent clouds, and their height might well have been $80 \mathrm{~km}$.

According to Prof. Størmer's observations, no iridescent clouds were visible for many years after 1892. The same seems to have been the case with luminous night clouds, for at midsummer for several years from $1892 \mathrm{I}$ searched for them in vain from vantage points in Essex. But the midnight sky near the horizon was never so clear as it was in 1885, as seen from the heart of London. T. S. Dymond.

St. Leonards-on-Sea, May 11.

1 Nature, 129, 497, April 2, 1932.

\section{Musical Sands}

The various theories referred to by "A. T. W." in the review.-" Nature and Man in Arabia"-published in Nature of April 30, have been so frequently and thoroughly criticised and tested since the publication of my first paper in 1888 , that one would have thought it unnecessary to revive the discussions now. However, I may point out that after having succeeded in producing musical sand artificially, it was admitted by Crookes, and other leading physicists, that I had proved my explanation of the cause of the sounds to be the correct one.

Some writers, who must have overlooked the details of my work, have disposed of the matter by stating that I ascribe the phenomenon to "friction" between the grains-which scarcely does justice to my theory. Friction only produces noise in unmusical sands.

Technically, the musical sounds are produced through the rhythmic acceleration of vibrations following abrupt frictional retardation. No other theory can account for the remarkable results that can be experimentally demonstrated with these sands. Unless the grains comply with the necessary physical conditions, no amount of friction will produce musical sounds.

It is scarcely correct to say that the late Lord Curzon, who corresponded with me for some time on the subject,1 " brought together all known sources of information on the subject".

\section{Carus-Wilson.}

${ }^{1}$ Nature, 113, 274, Feb. 23, 1924.

\section{The Neutron Hypothesis}

DR. J. CHADwick's explanation ${ }^{1}$ of the mysterious beryllium radiation is very attractive to theoretical physicists. Is it not possible to admit that neutrons play also an important rôle in the building of nuclei, the nuclei electrons being all packed in $\alpha$-particles or neutrons? The lack of a theory of nuclei makes, of course, this assumption rather uncertain, but perhaps it sounds not so improbable if we remember that the nuclei electrons profoundly change their properties when entering into the nuclei, and lose, so to say, their individuality, for example, their spin and magnetic moment.

The chief point of interest is how far the neutrons can be considered as elementary particles (something like protons or electrons). It is easy to calculate the number of $\alpha$-particles, protons, and neutrons for a given nucleus, and form in this way an idea about the momentum of nucleus (assuming for the neutron a moment $\frac{1}{2}$ ). It is curious that beryllium nuclei do not possess free protons but only $\alpha$-particles and neutrons.

Physico-Technical Institute, Leningrad, April 21.

NATURE, 129, 312, Feb. 27, 1932

No. 3265, Vor. 129] 